\title{
Evidence for a Streptococcal Superantigen-driven Process in Acute Guttate Psoriasis
}

\author{
Donald Y. M. Leung, ${ }^{\star \ddagger}$ Jeffrey B. Travers," Ralph Giorno, ${ }^{\S}$ David A. Norris," Robert Skinner, "Jacob Aelion," \\ Leslie V. Kazemi, * Michael H. Kim, ${ }^{* *}$ Anne E. Trumble, ${ }^{\star}$ Malak Kotb, ${ }^{\uparrow}$ and Patrick M. Schlievert** \\ *Department of Pediatrics, The National Jewish Center for Immunology and Respiratory Medicine, Denver, Colorado 80206; \\ Departments of ${ }^{\ddagger}$ Pediatrics, ${ }^{\S}$ Immunology, and ${ }^{\| D e r m a t o l o g y, ~ U n i v e r s i t y ~ o f ~ C o l o r a d o ~ H e a l t h ~ S c i e n c e s ~ C e n t e r, ~ D e n v e r, ~ C o l o r a d o ~ 80262 ; ~}$ \\ 'Departments of Medicine and Microbiology, University of Tennessee, Memphis, Tennessee 38163 and the Veteran's Administration \\ Medical Center, Memphis, Tennessee 38104; and **Department of Microbiology, University of Minnesota, Minneapolis, \\ Minnesota 55455
}

\begin{abstract}
Recent studies have suggested that $\mathbf{T}$ cells play a critical role in the pathogenesis of psoriasis. Guttate psoriasis is a well-defined form of psoriasis frequently associated with streptococcal throat infection. This study tested the hypothesis that $T$ cells in acute guttate psoriasis skin lesions may be activated by streptococcal superantigens. Peripheral blood as well as lesional and perilesional skin biopsies were analyzed for $T$ cell receptor $V \beta$ repertoire using monoclonal antibodies against 10 different $V \beta$ families. Skin biopsies from all patients with acute guttate psoriasis, but not skin biopsies from patients with acute atopic dermatitis or inflammatory skin lesions induced in normal subjects with sodium lauryl sulfate, demonstrated selective accumulation of $\mathrm{V} \beta 2+\mathrm{T}$ cells $(P<0.05)$. The expansion of $\mathrm{V} \beta 2+\mathrm{T}$ cells occurred in both the CD4+ and the $\mathrm{CD8}+\mathrm{T}$ cell subsets. Sequence analysis of $T$ cell receptor $\beta$ chain genes of $V \beta 2$ expressing $T$ cells from skin biopsies of patients with guttate psoriasis showed extensive junctional region diversity that is more compatible with a superantigen rather than a conventional (nominal) antigen-driven $T$ cell response. All streptococcal isolates from patients with guttate psoriasis secreted streptococcal pyrogenic exotoxin $\mathbf{C}$, a superantigen known to stimulate marked $\mathrm{V} \beta 2+\mathrm{T}$ cell expansion. These data support the concept that acute guttate psoriasis is associated with superantigenic stimulation of $T$ cells triggered by streptococcal superantigen(s). (J. Clin. Invest. 1995. 96:2106-2112.) Key words: psoriasis - superantigens $\cdot T$ cells • skin • Streptococci
\end{abstract}

\section{Introduction}

Psoriasis is a chronic inflammatory skin disorder associated with significant morbidity and occupational disability, affecting nearly $2 \%$ of the general population. The characteristic skin lesion in psoriasis consists of persistent erythematous plaques due to the infiltration of inflammatory cells and increased proliferation of keratinocytes (1). Immune activation, particularly of

Address correspondence to Donald Y. M. Leung, M.D., Ph.D., Dept. of Pediatrics, National Jewish Center for Immunology and Respiratory Medicine, 1400 Jackson St., Denver, CO 80206. Phone: 303-398-1186; FAX: 303-270-2182.

Received for publication 4 May 1995 and accepted in revised form 7 August 1995.

The Journal of Clinical Investigation, Inc

Volume 96, November 1995, 2106-2112
$\mathrm{T}$ cells, is thought to play a critical role in the pathogenesis of psoriasis. This concept is supported by the following observations: First, histologic examination of early skin lesions has demonstrated that epidermal hyperplasia is preceded by the infiltration of $\mathrm{T}$ lymphocytes and macrophages into the skin (2). Furthermore, T lymphocyte clones grown from psoriatic lesions release growth factors that induce keratinocyte proliferation (3). Second, certain subtypes of psoriasis exhibit a strong association with particular HLA types (4). Third, immunosuppressive drugs which inhibit $\mathrm{T}$ cell activation and cytokine secretion such as anti-CD3, corticosteroids, and cyclosporine A are very effective in treating psoriasis (5).

Despite increasing data supporting the concept that psoriasis is immunologically mediated, the actual early events that trigger this common skin condition are poorly understood. Guttate psoriasis is a well-defined form of psoriasis which erupts suddenly and is frequently associated with a preceding history of streptococcal throat infection or a rise in serum antistreptococcal titers $(6,7)$. Due to the acute nature of guttate psoriasis and its strong association with streptococcal throat infection, this disease offers a unique opportunity to link the nature of the T cell activation in this subtype of psoriasis with a potential etiologic agent. Recent studies demonstrating that streptococcal $\mathbf{M}$ proteins and streptococcal pyrogenic exotoxins (SPE) ${ }^{1}$ act as superantigens provide a potential mechanism by which streptococci could mediate the activation of skin-infiltrating $\mathrm{T}$ cells and monocytes in at least a subset of patients with psoriasis $(8-10)$.

The term "superantigen" refers to a group of microbial antigens that cause the marked expansion of $\mathrm{T}$ cells expressing specific $\mathrm{T}$ cell receptor (TCR) $\beta$ chain variable $(\mathrm{V} \beta)$ gene segments (for review see reference 10). In this regard, a recent report by Lewis et al. (11) described a marked overrepresentation of $\mathrm{V} \beta 2+\mathrm{T}$ cells in the acute skin lesions of patients with guttate psoriasis. It is important to note, however, that although these data are consistent with a superantigenic process, it does not exclude the possible involvement of a conventional antigen. An important distinguishing feature between superantigens and conventional peptide antigens is that superantigens stimulate $\mathrm{T}$ cells almost solely through the $\mathrm{V} \beta$ portion of the TCR and therefore induce an expansion of both CD4 + and CD8 $+\mathrm{T}$ cells. Other variable elements $(\mathrm{D} \beta, \mathrm{J} \beta, \mathrm{V} \alpha, \mathrm{J} \alpha)$ of the TCR are not generally involved in superantigen recognition. This is markedly different from $T$ cells activated by most conventional peptide antigens which frequently results in an expansion of only a subset of $\mathrm{CD} 4+$ or $\mathrm{CD} 8+\mathrm{V} \beta$-expressing cells with limited

1. Abbreviations used in this paper: SPE, streptococcal pyrogenic exotoxins; SSA, streptococcal superantigen; TCR, $\mathrm{T}$ cell receptor; $\mathrm{V} \beta$ variable region of the TCR $\beta$ chain. 
TCR junctional diversity. The present study was therefore carried out to determine whether $\mathrm{V} \beta 2+\mathrm{T}$ cell infiltration could be confirmed in an independent population of patients with acute guttate psoriasis from whom streptococcal isolates were characterized and to assess whether this increased $\mathrm{V} \beta 2$ expression was consistent with other features of superantigen stimulation.

\section{Methods}

Patients. 10 adult patients (6 females and 4 males) with acute guttate psoriasis were studied. Their age ranged from 26 to $41 \mathrm{yr}$ and their extent of skin disease ranged from 20 to $70 \%$ of their body surface area. Acute guttate psoriasis was defined as the sudden eruption of small ( $<2 \mathrm{~mm}$ ) erythematous macules which evolved into the parakeratotic maculopapules of psoriasis. In the majority of patients, the onset of the rash was preceded by a sore throat associated with either a positive throat culture for group A $\beta$-hemolytic streptococcus or elevated serum streptozyme titers. Their guttate psoriasis improved or completely cleared after oral antibiotic therapy. Blood as well as skin biopsies of untreated lesional skin and uninvolved perilesional skin of early acute guttate lesions ( $<1$ wk old) were taken from 8 of the 10 patients. Perilesional biopsies were obtained $1 \mathrm{~cm}$ from the skin lesion. Streptococcal isolates, but not skin biopsies, were obtained from the remaining two patients. As a control for inflammatory skin lesions, lesional and perilesional skin biopsies were procured from six adult patients with atopic dermatitis diagnosed according to the Hanifin and Rajka criteria (12). In addition, biopsies were obtained of irritant skin reactions induced in six normal subjects by sodium lauryl sulfate. In these experiments, $20 \mu \mathrm{l}$ of $2.5 \%$ ( $\mathrm{vol} / \mathrm{vol}$ ) solutions of sodium lauryl sulfate (Sigma Immunochemicals, St. Louis, MO) were placed in 8-mm-diameter Finn chambers (Epitest Ltd., Oy, Finland), applied to the volar forearm of six normal volunteers, and biopsied after $48 \mathrm{~h}$. Informed consent was obtained from all patients before performing all studies.

Characterization of streptococcal isolates. Streptococci isolated from the pharynx of patients with guttate psoriasis were typed for $\mathbf{M}$ and $\mathrm{T}$ proteins by the World Health Organization Collaborating Center for Reference and Research on Streptococci at the University of Minnesota using standard techniques (13). The presence of the SPEA and SPEC genes encoding for SPE proteins was determined by PCR as described previously (14). Inasmuch as all group A streptococcal strains harbor the SPEB gene, its detection by PCR would be noninformative. Thus, the expression of SPEB was determined by Ouchterlony immunodiffusion assay as described previously (15).

$m A b s$. mAb Leu4 (CD3; Peridin chlorophyll- $\alpha$ protein, i.e., PerCP), Leu3a (CD4; FITC, PE), Leu2a (CD8; PE), G1CL (mouse IgG1 control; FITC, PE), and G2GL (mouse IgG2 control; FITC, PE) were obtained from Becton Dickinson Immunocytometry Systems (San Jose, CA). Biotinylated or unconjugated mAbs specific for TCR $V \beta 2$, $\mathrm{V} \beta 13.1, \mathrm{~V} \beta 17$, and $\mathrm{V} \beta 19$ were obtained from Immunotech (Westbrook, $\mathrm{ME}$ ); mAbs directed to TCR V $\beta 3, \mathrm{~V} \beta 5.1, \mathrm{~V} \beta 5.2, \mathrm{~V} \beta 6.7, \mathrm{~V} \beta 8.1$, and $\mathrm{V} \beta 12$ were obtained from $\mathrm{T}$ Cell Sciences (Cambridge, MA). For tissue staining, an IgG anti-V $\beta 2$ antibody was used (kind gift from Prof. Arthur Boylston, University of Leeds, Leeds, United Kingdom).

Assessment of peripheral blood T cell repertoire. PBMC were isolated from heparinized blood by Ficoll-Hypaque density gradient centrifugation. TCR V $\beta$ repertoire on freshly isolated PBMC were assessed by two- or three-color immunofluorescence on a FACScan ${ }^{\circledR}$ flow cytometer (Becton Dickinson Immunocytometry Systems) using FITC, PE, and PerCP as the three fluorescent parameters as described previously (1618). List mode multiparameter data files (each file with forward scatter, side scatter, and three fluorescent parameters) were analyzed using the LYSIS II Windows program. Negative control reagents were used to verify the staining specificity of antibodies. The percentage of $T$ cells bearing each TCR $\mathrm{V} \beta$ phenotype was expressed as a percentage of total $\mathrm{T}(\mathrm{CD} 3+)$ cells.

Immunohistochemistry. Skin biopsies placed in OCT compound (Miles, Inc., Elkhart, IN) were flash frozen in liquid nitrogen and stored at $-80^{\circ} \mathrm{C}$. $4 \mathrm{~mm}$ cryostat sections were cut, dehydrated in acetone for $10 \mathrm{~min}$, and air dried. Sections were incubated for 30-60 min at room temperature with the respective anti- $\mathrm{V} \beta \mathrm{mAb}$ or anti-CD $\mathrm{mAb}$. Sections were then washed and stained by the labeled avidin biotin method as described previously $(19,20)$ using peroxidase-labeled streptavidin (Dako Corp., Carpinteria, CA). Afterwards, sections were counterstained with hematoxylin and mounted. For two-color staining, the sequential staining method developed by Wagner and Worman (21) was used with anti-V $\beta$ staining demonstrated by fast blue BB-naphthol ASMX, and anti-CD4 or CD8 staining demonstrated by fast red TR-naphthol AS-BI phosphate. Control antibodies were tested on step sections of the same tissue specimens. The negative staining controls were isotypespecific mouse immunoglobulins with irrelevant specificity. Normal human tonsil sections were used as positive controls for $\mathrm{V} \beta \mathrm{T}$ cell staining and $C D$ antibodies. All lymphocyte counts of stained sections were performed without knowledge of the subject's identity or condition. Two different investigators evaluated the skin biopsies. Interobserver variation was $<5 \%$. Results are expressed as a percentage of CD3, CD4, or $\mathrm{CD} 8$ reactive $\mathrm{T}$ cells.

Cloning and sequencing of TCR $\beta$ chain junctional regions. Total RNA (5-10 $\mu \mathrm{g}$ ) was extracted from homogenized skin biopsies by using Ultraspec RNA isolation solution (Biotecx Laboratories Inc., East Houston, TX). Reverse-transcribed total RNA (0.2 $\mu \mathrm{g}$; cDNA) was amplified by PCR using primers specific for the V $\beta 2$ TCR family and for the $3^{\prime} \mathrm{C} \beta$ primer as previously described $(16,17)$. The sequences of the primers were 5'-GGGAATTCTCATCAACCATGCAAGCCTGACCT-3' for $V \beta 2$, and $5^{\prime}$-GGGATCCTTCTGATGGCTCAAACAC$3^{\prime}$ for $\mathrm{C} \beta$. The $\mathrm{V} \beta$ and $\mathrm{C} \beta$ primers carried EcoRI or BamHI sites, respectively (underlined). After 35 cycles of PCR, amplified $\beta$ chain fragments were extracted with phenol-chloroform and precipitated with ethanol. Purified fragments were then digested with EcoRI and BamHI, ligated into plasmid pTZ18R (Pharmacia LKB Biotechnology Inc., Piscataway, NJ), and cloned. Double-stranded plasmid DNAs were prepared by alkali-lysis method and acid phenol extraction and were sequenced by Sequenase Ver 2.0 kit (United States Biochemical, Cleveland, $\mathrm{OH}$ ) following the manufacturer's recommendations (22).

Statistical analysis. Since the distribution of TCR $\mathrm{V} \beta$ expression often exhibited departure from normality, analyses were based on the natural logarithm of the $\mathrm{T}$ cell scores. Site (lesion versus perilesion) dependent differences in $\mathrm{T}$ cell expression for the guttate psoriasis group for each $\mathrm{V} \beta$ family and comparisons between the three study groups on lesion and perilesion site differences were made using repeatedmeasures ANOVA. Fisher's protected least significant difference was used to evaluate significant differences between pairs of means. The proportionate difference in SPEC positive-production between the present guttate psoriasis streptococci and toxic shock syndrome streptococci was assessed with a $\chi^{2}$ test. $P$ values of $<0.05$ were considered statistically significant.

\section{Results}

To determine whether acute guttate psoriasis is associated with the expression of a particular TCR V $\beta$ family, $\mathrm{T}$ lymphocytes in peripheral blood and frozen skin sections from eight patients with guttate psoriasis were analyzed for reactivity with $\mathrm{mAbs}$ specific for $10 \mathrm{TCR} V \beta$ families (Fig. 1). The T cell repertoire in the peripheral blood of these patients was similar to our previously published values on normal subjects $(16,17)$ and therefore did not demonstrate any evidence for expansion of $T$ cell populations expressing particular TCR $\mathrm{V} \beta$ gene segments.

As compared with peripheral blood $\mathrm{T}$ cell repertoire, however, a marked accumulation of $\mathrm{V} \beta 2+\mathrm{T}$ lymphocytes was observed in either the perilesional or acute skin lesions of all patients with guttate psoriasis. A representative photomicrograph of anti-V $\beta 2$ and anti-CD3 staining is shown in Fig. 2. Of interest in six of the eight patients, $\mathrm{V} \beta 2+\mathrm{T}$ cell expression was greater in perilesional skin as compared with acute skin 


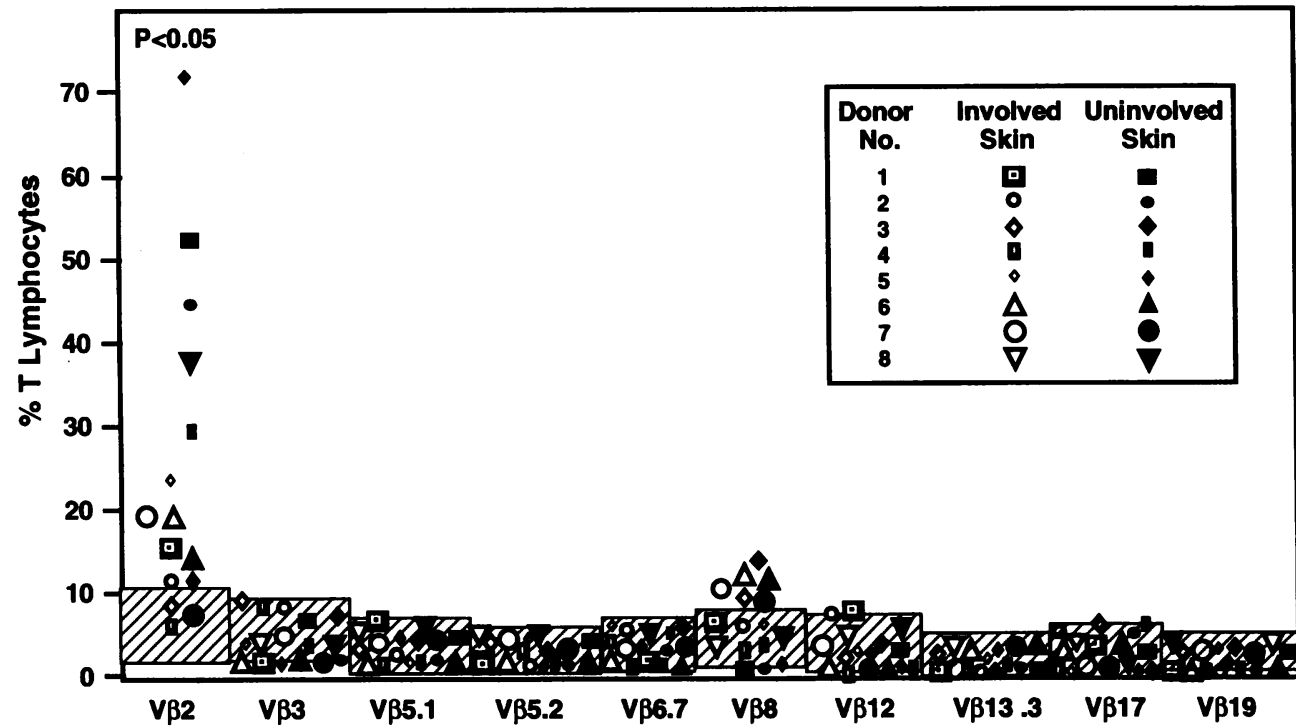

Figure 1. TCR $\mathrm{V} \beta$ expression in lesional versus perilesional skin of patients with guttate psoriasis. The cross-hatched areas represent the normal range (mean $\pm 2 \mathrm{SD})$ of $\mathrm{V} \beta$ families in the peripheral blood of patients with guttate psoriasis. $\mathrm{V} \beta 2$ was the only $\mathrm{V} \beta$ family that demonstrated a significant increase in lesional $(P<0.05)$ or perilesional skin $(P<0.05)$ as compared with peripheral blood. lesions. In two of the patients $>50 \%$ of the infiltrating $\mathrm{T}$ cells were $\mathrm{V} \beta 2+$, suggesting an important role for these $\mathrm{T}$ cells in the pathogenesis of guttate psoriasis. Occasional elevations were observed in the $\mathrm{V} \beta 8$ family (three patients). However, as a group, only the $\mathrm{V} \beta 2$ family demonstrated a significant expansion $(P<0.05)$.

To determine the specificity of $\mathrm{V} \beta 2$ expansion in guttate psoriasis, we analyzed the expression of $\mathrm{V} \beta 2$ in skin biopsies from patients with acute atopic dermatitis or inflammatory reactions induced by 48 -h sodium lauryl sulfate skin tests on normal individuals. As shown in Fig. 3, biopsies of perilesional and lesional skin of patients with acute guttate psoriasis demonstrated significantly higher $(P<0.01)$ percentages of $\mathrm{V} \beta 2+$ $T$ cells than biopsies of perilesional and lesional skin of patients with atopic dermatitis or sodium lauryl sulfate-induced irritant skin reactions.

Superantigens generally stimulate $T$ cells that bear a particular $\mathrm{V} \beta$ element independent of other cell surface proteins. Thus, superantigens usually stimulate TCR $\mathrm{V} \beta$ expansion in both the $\mathrm{CD} 4+$ and $\mathrm{CD} 8+\mathrm{T}$ cell subsets. We therefore analyzed the $\mathrm{V} \beta$ repertoire in CD4+ and CD8+ $\mathrm{T}$ cells by a two-color alkaline phosphatase staining technique in frozen skin biopsies from patients with guttate psoriasis. As compared with peripheral blood, there was an increased percentage of $\mathrm{V} \beta 2+\mathrm{T}$ cells in both the CD4 and the CD8 $+\mathrm{T}$ cell subsets of the skin infiltrate (Table I). Overrepresentation of $\mathrm{V} \beta 2+\mathrm{T}$ cells was observed in both the epidermis and the dermis.

Another important characteristic of superantigenic stimulation, as compared with stimulation by conventional peptide antigens, is that superantigens stimulate $\mathrm{T}$ cells almost exclusively through the $\mathrm{V} \beta$ portion of the TCR and therefore induce an expansion of $\mathrm{T}$ cells independent of their TCR junctional regions (for review see reference 10). This is different from $T$ cells activated by most conventional peptide antigens which frequently results in an expansion of only a subset of $\mathrm{V} \beta$ expressing cells with limited TCR junctional diversity.

To test the hypothesis that guttate psoriasis is triggered by a superantigen, we cloned and analyzed the sequences of random cDNA clones containing PCR-amplified $\mathrm{V} \beta 2$ chain genes of $\mathrm{T}$ cells from the skin of three patients with acute guttate psoriasis. In these experiments, RNA was directly extracted from skin biopsies of three patients in whom between 34 and $71 \%$ of $\mathrm{T}$ cells expressed $\mathrm{V} \beta 2$ as determined by mAb reactivity with immunoperoxidase staining (Fig. 1). $60 \mathrm{~V} \beta 2$ cDNA clones
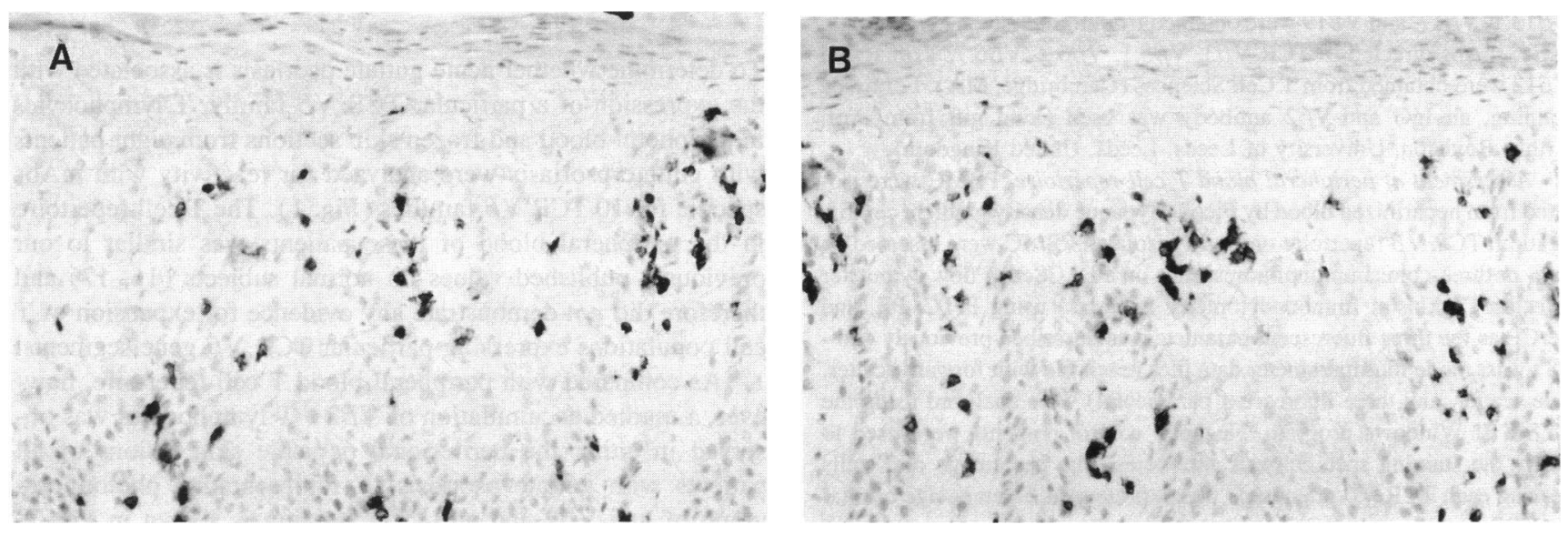

Figure 2. Frozen tissue sections from lesional skin biopsy of patient with guttate psoriasis stained with either monoclonal anti-V $\beta 2(A)$ or anti$\mathrm{CD} 3(B)$ and counterstained with hematoxylin. Most of the T cells in the epidermal and dermal cell infiltrate reacted with anti-V $\beta 2 . \times 256$ 


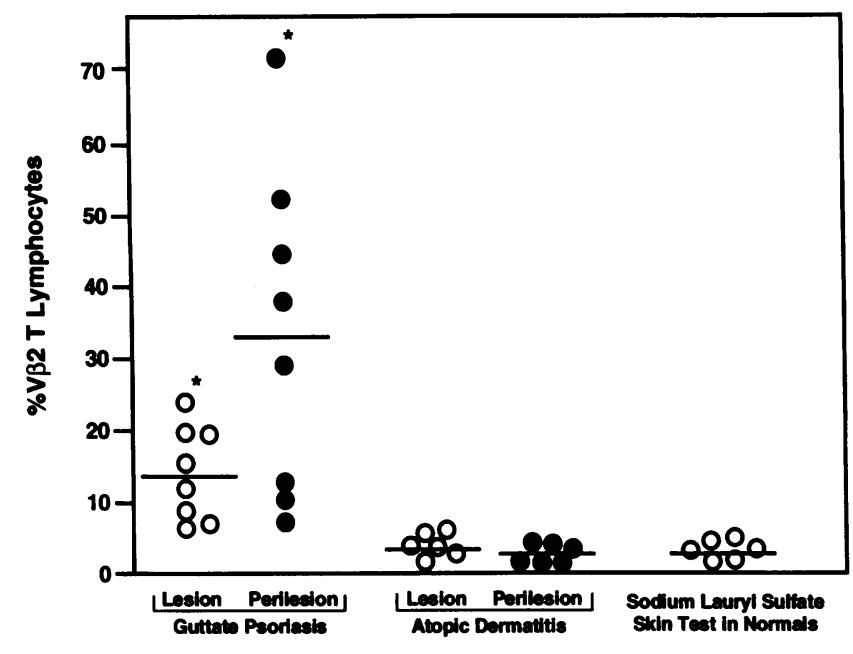

Figure 3. A comparison of $\mathrm{T}$ cell receptor $\mathrm{V} \beta 2$ expression in lesional versus perilesional skin of patients with guttate psoriasis versus atopic dermatitis, or sodium lauryl sulfate-induced skin test reactions in normal subjects. * As a group the $\mathrm{V} \beta 2$ expression in skin biopsies from patients with guttate psoriasis was significantly greater than in biopsies from the other two study groups $(P<0.01)$

were derived from these 3 patients. Since there was a 3-7-fold increase in $\mathrm{V} \beta 2+\mathrm{T}$ cell expression in their skin as compared with peripheral blood, in a clonotypic expansion of $\mathrm{V} \beta 2+\mathrm{T}$ cells, $67-87 \%$ of the clones would be expected to have identical junctional sequences. However, as shown in Table II, none of the $\mathrm{V} \beta 2$ clones had the same junctional sequence, and considerable diversity among the sequences within each individual was apparent. The CDR3 regions varied greatly in terms of residue number and sequence, and a conserved motif was not apparent.

Finally, we isolated group A Streptococci from seven patients with acute guttate psoriasis. As shown in Table III, there was no common $\mathrm{M}$ or $\mathrm{T}$ type among these isolates. Furthermore, these isolates did not consistently produce either SPEA or SPEB. However, all seven isolates produced SPEC, a superantigen known to induce the expansion of $\mathrm{T}$ cells expressing the $\mathrm{V} \beta 2$ gene segment (22). Of interest, several of the isolates also secrete SPEA or SPEB which are known to stimulate $\mathrm{V} \beta 8+\mathrm{T}$ cell expansion $(9,23)$. As a comparison, we have previously analyzed 34 consecutive isolates of group A streptococci from toxic shock syndrome patients (24) and 75 isolates from streptococcal infections other than toxic shock syndrome (25). The streptococcal toxic shock syndrome isolates predominantly expressed $M$ protein types 1 and 3 , and consistently produced SPEA and SPEB, but only occasionally produced SPEC. Using a $\chi^{2}$ analysis to compare the proportion of SPEC-producing streptococci in our guttate psoriasis patients versus the previous group of streptococci from toxic shock syndrome patients (24), a significant difference was observed between these two groups of isolates $(P<0.0001)$. Of the 75 isolates from a variety of other streptococcal diseases only $30 \%$ made SPEA, 63\% made SPEB, and $67 \%$ made SPEC (25).

Taken together, these data suggest that streptococci isolated from guttate psoriasis versus toxic shock syndrome have significantly different profiles of superantigen expression and that isolates associated with guttate psoriasis are more like isolates from other streptococcal infections. The complete nucleotide sequence of SPEC from one of the guttate psoriasis isolates was also determined (data not shown). The translated amino acid sequence was the same as that previously seen for SPEC (26).

\section{Discussion}

Previous investigations have identified a number of factors which may play a role in the pathogenesis of psoriasis. These include keratinocyte proliferation, vascular endothelial activation, $\mathrm{T}$ lymphocyte activation, neutrophil infiltration, and activation of dermal macrophages. Many of these pathologic features, however, likely reflect downstream events which have occurred as the result of immune activation and skin inflammation. Indeed, careful histologic examination of early psoriatic lesions has demonstrated that activation of $T$ lymphocytes, endothelial cells, and macrophages precedes epidermal proliferation (2). Furthermore, immunosuppressive drugs such as cyclosporin and FK506, whose primary action is the selective inhibition of cytokine production by activated $\mathrm{T}$ cells, are effective in treating psoriasis (5). Treatment with anti-T cell $\mathrm{mAbs}$ has also been found to clear psoriatic lesions (27). Conversely, $\mathrm{T}$ cell clones derived from psoriatic skin lesions can promote keratinocyte proliferation in vitro $(3)$.

The mechanisms by which $\mathrm{T}$ cells, keratinocytes, and macrophages achieve and maintain their activated state in psoriatic skin lesions are poorly understood. Although multiple factors may contribute to the exacerbation of psoriasis, there are many reports suggesting that bacterial infection can trigger this illness $(6,7,28,29)$. The relationship between bacterial infection and exacerbation of psoriasis is perhaps most clearly demonstrated in guttate psoriasis where there are multiple reports demonstrating that acute exacerbation of guttate psoriasis, in the majority of patients, is preceded by antecedent infection with group A streptococci and rises in serum antistreptococcal titers $(6,7)$. Patients with this form of psoriasis frequently improve with systemic antibiotic therapy (30).

In support of these clinical observations, Cole and Wuepper (31) first reported that alcohol precipitates of cell-free culture filtrates from Streptococcus pyogenes (strain NY-5) induced increased keratinocyte proliferation after intradermal injection into rabbit skin. These culture filtrates also had marked mitogenic activity upon human cultured lymphoid cells and are now known to have contained high levels of the streptococcal superantigens, SPEA, B, and C. Subsequently, it was reported that

Table I. TCR V $\beta 2$ Expression on $C D 4^{+}$versus $C D 8^{+} T$ Cell Subsets in Guttate Psoriasis

\begin{tabular}{|c|c|c|c|c|c|c|}
\hline \multirow[b]{2}{*}{ Patient } & \multicolumn{3}{|c|}{$\begin{array}{l}\text { Percent } \mathrm{V} \beta 2^{+} \text {in the } \mathrm{CD}^{+} \\
\text {subset }\end{array}$} & \multicolumn{3}{|c|}{$\begin{array}{c}\text { Percent } \mathrm{V} \beta 2^{+} \text {in the } \mathrm{CD}^{+} \\
\text {subset }\end{array}$} \\
\hline & Dermis & Epidermis & PBMC & Dermis & Epidermis & PBMC \\
\hline 1 & 30 & 43 & 5 & 21 & 30 & 3 \\
\hline 2 & 26 & 41 & 7 & 27 & 30 & 4 \\
\hline 3 & 12 & 40 & 8 & 14 & 20 & 6 \\
\hline 4 & 27 & 36 & 8 & 24 & ND & 7 \\
\hline Mean $\pm S D$ & $24 \pm 4 *$ & $40 \pm 1 *$ & $7 \pm 1$ & $22 \pm 3 *$ & $27 \pm 3 *$ & $5 \pm 1$ \\
\hline
\end{tabular}

$* P<0.05$ as compared with percent $\mathrm{V} \beta 2+\mathrm{T}$ cells in the corresponding peripheral blood T cell subset. Patient 4 had a predominance of CD4+ $\mathrm{T}$ cells in her epidermal infiltrate and therefore too few CD8+ cells to count. 
Table II. Analysis of TCR $\beta$ Chain Junctional Sequences Containing V $\beta 2$ Gene Segments from Three Patients with Guttate Psoriasis*

\begin{tabular}{|c|c|c|c|c|c|c|c|c|c|c|c|}
\hline \multicolumn{4}{|c|}{ Psoriasis patient 1} & \multicolumn{4}{|c|}{ Psoriasis patient 2} & \multicolumn{4}{|c|}{ Psoriasis patient 3} \\
\hline \multirow{2}{*}{$\frac{\mathrm{v} \beta}{\mathrm{CSAR}}$} & \multirow{2}{*}{$\begin{array}{l}\mathrm{ND} \beta \mathrm{N} \\
\mathrm{RD}\end{array}$} & \multicolumn{2}{|c|}{$\mathbf{J} \beta$} & \multirow{2}{*}{$\frac{\mathrm{V} \beta}{\mathrm{CSAR}}$} & \multirow{2}{*}{$\frac{\mathrm{ND} \beta \mathrm{N}}{\mathrm{AIPA}}$} & \multicolumn{2}{|c|}{$\mathrm{J} \beta$} & \multirow{2}{*}{$\frac{\mathrm{v} \beta}{\mathrm{CSA}}$} & \multirow{2}{*}{$\frac{\mathrm{ND} \beta \mathrm{N}}{\mathrm{VK}}$} & \multicolumn{2}{|c|}{$\mathrm{J} \gamma$} \\
\hline & & TEAF & $(1.1)$ & & & TEAF & $(1.1)$ & & & TEAF & (1.1) \\
\hline CSAR & VGI & YGYT & $(1.2)$ & CSA & ATRQ & TEAF & $(1.1)$ & CSA & VAM & TEAF & (1.1) \\
\hline CSA & FY & YGYT & $(1.2)$ & CSA & RS & TEAF & (1.1) & CSAR & $\mathrm{L}$ & TEAF & (1.1) \\
\hline CSA & RSL & EKL & (1.4) & CSA & HWA & YGYT & (1.2) & CSA & KREG & YGYT & (1.2) \\
\hline CSA & ATRK & SPLH & (1.6) & CSA & DT & YGYT & $(1.2)$ & CSA & LNRAD & NTIY & (1.3) \\
\hline CSA & SRDQS & NEQF & (2.1) & CSA & NNAE & YGYT & (1.2) & CSA & LGTM & NEKL & (1.4) \\
\hline CSA & PGPC & NEQF & (2.1) & CSAR & QLSEGG & NTIY & $(1.3)$ & CSA & $\mathrm{H}$ & NEKL & (1.4) \\
\hline CSAR & TQEC & NEQF & $(2.1)$ & CSA & RSGT & NEKL & (1.4) & CSAR & EGRP & NQPQH & (1.5) \\
\hline CSA & GISW & NEQF & (2.1) & CSAR & PTAR & SYNEQF & (2.1) & CSAR & IGGA & NEQF & (2.1) \\
\hline CSAR & ERAY & NEQF & (2.1) & CSA & TNA & SYNEQF & (2.1) & CSA & APSLQ & $\mathrm{NEQF}$ & (2.1) \\
\hline CSA & VSTR & NEQF & $(2.1)$ & CSA & KRPSG & SYNEQF & $(2.1)$ & CSA & VTRG & NEQF & (2.1) \\
\hline CSAR & LRFY & NEQF & $(2.1)$ & CSA & GTNRLG & SYNEQF & $(2.1)$ & CSAR & WYGA & NEQF & (2.1) \\
\hline CSA & PSGGA & GELF & $(2.2)$ & CSA & $\mathrm{G}$ & SYNEQF & (2.1) & CSAR & KG & TGELF & (2.2) \\
\hline CSAR & GGVG & ETQY & (2.5) & CSA & MHS & SYNEQF & (2.1) & CSA & IL & NIQY & (2.4) \\
\hline CSAR & VSASN & ETQY & (2.5) & CSA & EETQSL & TGELF & $(2.2)$ & CSA & AES & ETQY & (2.5) \\
\hline CSAR & HAT & ETQY & (2.5) & CSA & VVTQLRG & GELF & $(2.2)$ & CSA & PQN & ETQY & (2.5) \\
\hline CSAR & IVGLG & ETQY & (2.5) & CSAR & QRAV & TDTQ & (2.3) & CSAR & ARYY & GANVL & (2.6) \\
\hline CSA & PGLAK & ETQY & (2.5) & $\mathrm{CSA}$ & MVALG & NIQY & $(2.4)$ & CSA & VK & GANVL & (2.6) \\
\hline CSA & GDRGE & SYEQY & (2.7) & CSAR & DERYGG & QETQY & (2.5) & CSA & TQEG & SYEQY & (2.7) \\
\hline CSAR & VQEV & SYEQY & (2.7) & $\mathrm{CSA}$ & LWHT & QETQY & $(2.5)$ & & & & \\
\hline
\end{tabular}

* Results are expressed as derived amino acid sequences.

psoriatic lesions could be induced by intradermal injection of small amounts of killed streptococcal material (28). Furthermore, in vitro, both guttate and chronic plaque psoriasis patients have been shown to have enhanced $T$ lymphocyte responses to group A streptococcal antigens (32). These observations suggested the hypothesis that bacterial toxins derived from streptococci, acting as superantigens, could mediate the activation of infiltrating $\mathrm{T}$ cells and monocytes in at least a subset of patients with psoriasis.

In this report, we have demonstrated that there is selective accumulation of $\mathrm{V} \beta 2+\mathrm{T}$ cells infiltrating into the perilesional and lesional skin of patients with guttate psoriasis. This bias for the use of $V \beta 2$-encoded gene products was not seen in perilesional or lesional skin from patients with atopic dermatitis, or inflammatory skin lesions induced by sodium lauryl sulfate in normal subjects. No increases in $\mathrm{V} \beta 2+\mathrm{T}$ cells have been

Table III. Characteristics of Group A Streptococci Isolates from Throat Cultures of Patients with Guttate Psoriasis

\begin{tabular}{cccllll}
\hline & \multicolumn{3}{c}{ Typing } & & \multicolumn{3}{c}{ Pyrogenic exotoxins } \\
\cline { 2 - 3 } \cline { 6 - 7 } Patient & M & T & & SPEA & SPEB & SPEC \\
\hline 1 & 4 & 4 & & Negative & Negative* & Positive \\
2 & 1 & 1 & & Positive & Negative* & Positive \\
3 & Nontypeable & 12 & & Positive & Positive & Positive \\
4 & 18 & 27 & & Negative & Negative & Positive \\
5 & Unknown & Unknown & & Negative & Negative & Positive \\
6 & Unknown & Unknown & & Negative & Negative & Positive \\
7 & 4 & 4 & Negative & Negative & Positive
\end{tabular}

* Variable expression of SPEB. observed in normal skin although $\mathrm{V} \beta 1,-7,-14$, and $-16+\mathrm{T}$ cells have been reported to be frequently highly expressed in normal skin relative to peripheral blood (33). Thus, the observed $\mathrm{V} \beta 2+\mathrm{T}$ cells in guttate psoriasis skin lesions do not appear to be due to nonspecific skin inflammation.

We used immunocytochemistry and mAbs directed against specific TCR $\mathrm{V} \beta$ families to avoid the criticism of selection bias that has been associated with use of semiquantitative PCR techniques to analyze $\mathrm{V} \beta$ repertoire. The $10 \mathrm{mAbs}$ used in this study detect $\sim 50 \%$ of the $\mathrm{T}$ cell repertoire. Therefore, a potential criticism of our study is that we could have missed the increase of a $\mathrm{V} \beta$ family that was not stained for with our panel of $\mathrm{mAbs}$. This would appear unlikely because $\mathrm{V} \beta 2+\mathrm{T}$ cells accounted for over $50 \%$ of the $\mathrm{T}$ cell infiltrate in some lesions. Furthermore, in selected skin lesions, we have used a previously published semiquantitative PCR technique to analyze TCR repertoire in guttate psoriasis lesions and found primarily overexpression of the $\mathrm{V} \beta 2$ gene product (Trumble, A. E., and D. Y. $M$. Leung, unpublished observations).

Our data are consistent with a report by Lewis et al. (11) who also described a increased expression of $\mathrm{V} \beta 2+\mathrm{T}$ cells in the acute skin lesions of patients with guttate psoriasis. In our study, however, we provide further support for the concept that the $\mathrm{V} \beta 2+\mathrm{T}$ cell expansion in guttate psoriasis is the result of superantigen activation. In this regard, we have found that there was selective expansion of $\mathrm{V} \beta 2+$ cells in both the CD4 and the CD8+ infiltrating $\mathrm{T}$ cells in the dermis and epidermis of guttate psoriasis skin (Table I). More importantly, sequence analysis of TCR $\beta$ chain genes of $\mathrm{V} \beta 2$-expressing T cells in the skin from patients with guttate psoriasis showed extensive junctional region diversity (Table II).

In view of the marked selective expansion of $\mathrm{V} \beta 2+\mathrm{T}$ cells in acute guttate psoriasis, the extensive $\beta$ chain junctional diver- 
sity suggests that these $\mathrm{V} \beta$ s play a dominant role in recognition. This type of recognition is not characteristic of responses to most peptide antigens (10). A complex response to multiple antigens or epitopes seems unlikely since multiple $\mathrm{V} \beta$ regions would be expected to be involved. Taken together, this high frequency of response and the prominent role for $\mathrm{V} \beta 2$ are most consistent with the hypothesis that $\mathrm{T}$ cell activation during the acute phase of guttate psoriasis is mediated by a superantigen which induces $\mathrm{V} \beta 2$ expansion.

To identify a superantigen which might be involved in the activation of $\mathrm{V} \beta 2+\mathrm{T}$ cell activation in guttate psoriasis, we analyzed streptococcal isolates from these patients by $\mathrm{M}$ typing and secretion of pyrogenic exotoxins A, B, and C. Similar to previous studies, streptococci from our patients did not express any consistent $M$ protein type (34). Some of the isolates secreted SPEA or SPEB, which could explain the expansion of $\mathrm{V} \beta 8$ seen in some patients. Interestingly, all streptococci secreted SPEC, a superantigen known to stimulate the marked expansion of $\mathrm{V} \beta 2+\mathrm{T}$ cells (23). We did not test isolates in this study for two recently described superantigens, streptococcal superantigen (SSA) and SPEF $(35,36)$. It is highly unlikely that SSA was made by all of the isolates in this study since it has been shown that only selected $M$ types of streptococci, not including M1 and M18, for example, make SSA. In contrast, all of the isolates in our study likely also made SPEF since in addition to SPEC all isolates tested in a previous study (36) from a variety of streptococcal diseases made SPEF (35). SPEF stimulates $\mathrm{T}$ cells bearing $\mathrm{V} \beta 2$ as well as $\mathrm{V} \beta 4,8,15$, and 19. However, the consistent expression of SPEC by streptococci from guttate psoriasis patients suggests that it may have an important role in the pathogenesis of this disease.

Although a remarkable accumulation of $\mathrm{V} \beta 2+\mathrm{T}$ cells has now been reproducibly found in independent studies to occur in the epidermis and dermis of patients with guttate psoriasis, analyses of $T$ cell repertoire in the skin lesions of patients with chronic plaque psoriasis have yielded inconsistent results. In one study, Chang et al. (37) found that CD8+, but not CD4+, $\mathrm{T}$ cells in the epidermis of psoriatic plaques from five patients preferentially used $\mathrm{V} \beta 3$ and/or $\mathrm{V} \beta 13.1$ genes. Sequence analyses of these two $\mathrm{V} \beta$ genes demonstrated monoclonality or marked oligoclonality. In two patients in which $\mathrm{V} \beta 3$ and/or $\mathrm{V} \beta 13.1$ was not increased, an increase in $\mathrm{V} \beta 17$ gene use and clonality was found. In a separate study, by Boehncke et al. (38), only three of nine patients with chronic plaque psoriasis showed evidence of TCR V $\beta$ skewing of their skin-infiltrating $T$ cells. In these cases, there was a marked accumulation of intraepidermal $\mathrm{V} \beta 19$ and/or $\mathrm{V} \beta 22+\mathrm{T}$ cells. In contrast, the study by Lewis et al. (11) reported a predominance of $\mathrm{V} \beta 2+$ $T$ cells in the skin infiltrate of the majority of patients with chronic plaque psoriasis. These data suggest that the host factors and immunologic triggers likely differ in guttate versus chronic plaque psoriasis.

In the case of acute guttate psoriasis, induction of psoriatic lesions occurs after pharyngeal infection with superantigen-secreting streptococci. To date, we have been unable to recover streptococci or staphylococci from the local skin lesions of these patients (Leung, D. Y. M., J. B. Travers, and D. A. Norris, unpublished observations ). Since these patients do not develop toxic shock and there is no evidence for $\mathrm{V} \beta$ expansion of circulating $\mathrm{T}$ cells, we postulate that after streptococcal pharyngitis, skin-seeking $\mathrm{T}$ cells are induced in lymph nodes draining the pharynx, i.e., at a site distant from the skin. After activation, these $\mathrm{T}$ cells then home to the skin via (CLA)/E-selectin inter- actions and may be locally activated further in psoriatic patients by a skin-specific antigen that is recognized by $\mathrm{V} \beta 2+\mathrm{T}$ cells. This hypothesis is consistent with our observation that the percentage of $\mathrm{V} \beta 2+\mathrm{T}$ cells in the perilesional skin was higher than that found in the actual guttate psoriasis lesion. In further support of this concept, we have also found recently that SPEC and other bacterial superantigens potently induce the expression of the skin homing receptor (CLA) on T lymphocytes, in an IL-12-dependent manner (18).

Nearly $70 \%$ of patients with guttate psoriasis develop chronic plaque psoriasis. In such patients, superantigens may activate skin-infiltrating autoreactive $T$ cells which remain persistently activated due to the abnormal recognition of specific skin antigens (39). The additional factors which determine whether patients have self-limited guttate psoriasis or develop chronic plaque psoriasis are unknown but presumably depend in large part on host genetic factors which are involved in antigen-binding, e.g., HLA molecules, as well as the actual antigen-triggering $T$ cell activation. Indeed, chronic psoriasis has been associated with the HLA-Cw6 allele and a raised incidence of DR7 (4). Recent oligonucleotide typing studies have also revealed a strong association with the extended HLADRB1 *0701/2,DQA1 *0201,DQB1 *0303 haplotype (40).

The previous reports documenting the involvement of CD8 $+\mathrm{T}$ cells bearing different TCR V $\beta$ s, that are clonally expanded in chronic plaque psoriasis, suggest that these $\mathrm{T}$ cells have been expanded in situ in response to an antigen(s) in the skin. Potential candidate skin autoantigens include keratins (41) or carbohydrates (42), which have crossreactive determinants with bacterial antigens. Alternatively, some bacterial-derived superantigen may be accumulated by either cutaneous professional (43) or nonprofessional antigen (44) presenting cells and thereby may locally activate the $\mathrm{T}$ cells to induce keratinocyte proliferation. Of interest, there have been reports of patients with plaque psoriasis who had exacerbation of their skin disease after cutaneous infection with superantigen-secreting $S$. aureus or Candida albicans (20). Since the perilesional skin, which has increased $\mathrm{V} \beta 2+\mathrm{T}$ cells, does not necessarily become a lesion, there is probably a second event in the skin which is needed for complete evolution of the clinical psoriatic skin lesion.

In conclusion, our study provides strong evidence that guttate psoriasis is triggered by streptococcal superantigen $(\mathrm{s})$. The extent to which other types of psoriasis are also induced by superantigens requires further study. It is highly likely, however, that psoriasis will be associated with a number of microbial and nonmicrobial triggers. The inability to find microbial triggers for other forms of chronic psoriasis may stem from the lack of a clear starting point to their disease. Acute guttate psoriasis may therefore be an important model to examine early events in the triggering of psoriasis. Identification of the $T$ cells and triggers involved in psoriasis will be critical for the examination of early upstream events involved in its pathogenesis and allow the development of more effective and specific therapeutic targets in this important skin disorder.

\section{Acknowledgments}

The authors wish to thank Dr. David Iklé and Dr. David McCormack for their assistance in statistical analyses of our data, as well as Maureen Plourd-Sandoval for her assistance in the preparation of this manuscript.

This work was supported in part by National Institutes of Health grants AR-41256, HL-37260, RR-00051, and AR-07411 and The National Psoriasis Foundation. 


\section{References}

1. Nickoloff, B. J. 1991. The cytokine network in psoriasis. Arch. Dermatol. 127:871-884

2. Krueger, J. G., J. F. Krane, D. M. Carter, and A. B. Gottlieb. 1990. Role of growth factors, cytokines, and their receptors in the pathogenesis of psoriasis. J. Invest. Dermatol. $94: 135 \mathrm{~s}-140$ s.

3. Strange, P., K. D. Cooper, E. R. Hansen, G. Fisher, J. K. Larsen, D. Fox C. Krag, J. J. Voorhees, and O. Baadsgaard. 1993. T-lymphocyte clones initiated from lesional psoriatic skin release growth factors that induce keratinocyte proliferation. J. Invest. Dermatol. 101:695-700.

4. Baker, B. S., A. F. Swain, L. Fry, and H. Valdimarsson. 1984. Epidermal T lymphocytes and HLA-DR expression in psoriasis. Br. J. Dermatol. 110:555564.

5. Ellis, C. N., D. C. Gorsulowsky, T. A. Hamilton, J. Billings, M. Brown, J. Headington, K. Cooper, O. Baadsgaard, E. Duell, and T. Annesley. 1986 Cyclosporine improves psoriasis in a double-blind study. JAMA (J. Am. Med. Assoc.) 256:3110-3116.

6. Henderson, C. A., and A. S. Highet. 1988. Acute psoriasis associated with Lancefield group $\mathrm{C}$ and group $\mathrm{G}$ cutaneous streptococcal infections. $\mathrm{Br}$. $J$. Dermatol. 118:559-562.

7. Whyte, J. H., and R. D. Baughman. 1964. Acute guttate psoriasis and streptococcal infection. Arch. Dermatol. 89:350-356.

8. Tomai, M., M. Kotb, G. Majumdijar, and E. H. Beachey. 1990. Superantigenicity of streptococcal M protein. J. Exp. Med. 172:359-362.

9. Abe, J., J. Forrester, T. Nakahara, J. A. Lafferty, B. L. Kotzin, and D. Y. M Leung. 1991. Selective stimulation of human T cells with streptococcal erythrogenic toxins A and B. J. Immunol. 146:3747-3750.

10. Kotzin, B. L., D. Y. M. Leung, J. Kappler, and P. Marrack. 1993. Superantigens and human disease. Adv. Immunol. 54:99-166.

11. Lewis, H. M., B. S. Baker, S. Bokth, A. V. Powles, J. J. Garioch, H Valdimarsson, and L. Fry. 1993. Restricted T-cell receptor $\mathrm{V} \beta$ gene usage in the skin of patients with guttate and chronic plaque psoriasis. Br. J. Dermatol. 129:514-520.

12. Hanifin, J. M., and G. Rajka. 1980. Diagnostic features of atopic dermatitis. Acta Dermatol-Venereol. (Stockh.). 92:44-47.

13. Stevens, D. L., M. H. Tanner, J. Winship, R. Swarts, K. M. Ries, P. M. Schlievert, and E. Kaplan. 1989. Severe group A streptococcal infections associated with a toxic shock-like syndrome and scarlet fever toxin A. N. Engl. J. Med. 321:1-7.

14. Tyler, S. D., W. M. Johnson, and J. C. Huang. 1992. Streptococcal erythrogenic toxin genes: detection by polymerase chain reaction and association with disease in strains isolated in Canada from 1940 to 1991. J. Clin. Microbiol. 30:3127-3131.

15. Lee, P. K., and P. M. Schlievert. 1989. Quantification and toxicity of group A streptococcal pyrogenic exotoxins in an animal model of toxic shock syndrome-like illness. J. Clin. Microbiol. 27:1890-1894.

16. Abe, J., B. L. Kotzin, K. Jujo, M. E. Melish, M. P. Glode, T. Kohsaka and D. Y. M. Leung. 1992. Selective expansion of $T$ cells expressing $T$ cel receptor variable regions $\mathrm{V} \beta 2$ and $\mathrm{V} \beta 8$ in Kawasaki disease. Proc. Natl. Acad. Sci. USA. 89:4066-4070.

17. Abe, J., B. L. Kotzin, C. Meissner, M. E. Melish, T. Masato, D. Fulton F. Romagne, B. Malissen, and D. Y. M. Leung. 1993. Characterization of T cell repertoire changes in acute Kawasaki disease. J. Exp. Med. 177:791-796.

18. Leung, D. Y. M., M. Gately, A. Trumble, B. Ferguson-Darnell, P. M. Schlievert, and L. J. Picker. 1995. Bacterial superantigens induce T cell expression of the skin-selective homing receptor, the cutaneous lymphocyte-associated antigen (CLA). J. Exp. Med. 181:747-753.

19. Giorno, R. 1984. Technical considerations in immunohistology of lymphoid cell membrane antigens. Surv. Synth. Pathol. Res. 3:165-188.

20. Leung, D. Y. M., P. Walsh, R. Giorno, and D. A. Norris. 1993. A potential role for superantigens in the pathogenesis of psoriasis. J. Invest. Dermatol. 100:225-228.

21. Wagner, L., and C. P. Worman 1988. Color-contrast staining of two different lymphocyte subpopulations: a two-color modification of alkaline phosphatase monoclonal anti-alkaline phosphatase complex technique. Stain Technol. 63:129-136.

22. Toneguzzo, F., S. Glynn, E. Levi, S. Mjolsness, and A. Hayday. 1988.
Use of a chemically modified T7 DNA polymerase for manual and automated sequencing of supercoiled DNA. Biotechniques. 6:460-469.

23. Tomai, M. A., P. M. Schlievert, and M. Kotb. 1992. Distinct T-cell receptor $\mathrm{V}$ beta gene usage by human $\mathrm{T}$ lymphocytes stimulated with the streptococcal pyrogenic exotoxins and pep M5 protein. Infect. Immun. 60:701-705.

24. Hauser, A. R., D. L. Stevens, E. L. Kaplan, and P. M. Schlievert. 1991 Molecular analysis of pyrogenic exotoxins from Streptococcus pyrogenes isolates associated with toxic shock-like syndrome. J. Clin. Microbiol. 29:1562-1567.

25. Schlievert, P. M., K. M. Bettin, and D. W. Watson. 1979. Production of pyrogenic exotoxin by groups of streptococci: association with group A. J. Infect. Dis. 140:676-680.

26. Kapur, V., K. Nelson, P. M. Schlievert, R. K. Selander, and J. M. Musser 1992. Molecular population genetic evidence of horizontal spread of two alleles of the pyrogenic exotoxin $\mathrm{C}$ gene (speC) among pathogenic clones of Streptococcus pyogenes. Infect. Immun. 60:3513-3517.

27. Morel, P., J. P. Revillard, J. F. Nicolas, J. Wijdenes, H. Rizova, and J. Thivolet. 1992. Anti-CD4 monoclonal antibody therapy in severe psoriasis. $J$. Autoimmun. 5:465-477.

28. Rosenberg, E. W., and P. W. Noel. 1988. The Koebner phenomenon and the microbial basis of psoriasis. J. Am. Acad. Dermatol. 18:151-158.

29. Marples, R. R., C. L. Heaton, and A. M. Kligman. 1973. Staphylococcus aureus in psoriasis. Arch. Dermatol. 107:568-570.

30. Rosenberg, E. W., P. W. Noah, M. D. Zanolli, R. B. Skinner, M. J. Bond and N. Crutcher. 1986. Use of rifampin with penicillin and erythromycin in the treatment of psoriasis. J. Am. Acad. Dermatol. 14:761-764.

31. Cole, G. W., and K. D. Wuepper. 1978. Isolation and partial characterization of a keratinocyte proliferative factor produced by Streptococcus pyogenes (strain NY-5). J. Invest. Dermatol. 71:219-223.

32. Baker, B. S., S. Bokth, A. Powles, J. J. Garioch, H. Lewis, H. Valdimarsson, and L. Fry. 1993. Group A streptococcal antigen-specific T lymphocytes in guttate psoriatic lesions. Br. J. Dermatol. 128:439-499.

33. Dunn, D. A., A.-S. Gadenne, S. Simha, E. A. Lerner, M. Bigby, and P. A Bleicher. 1993. T-cell receptor V $\beta$ expression in normal human skin. Proc. Natl. Acad. Sci. USA. 90:1267-1271.

34. Telfer, N., R. Chalmers, K. Whale, and G. Colman. 1992. The role of streptococcal infection in the initiation of guttate psoriasis. Arch. Dermatol 128:39-42.

35. Reda, K. B., V. Kapur, J. A. Mollick, J. G. Lamphear, J. M. Musser, and R. R. Rich. 1994. Molecular characterization and phylogenetic distribution of the streptococcal superantigen gene (ssa) from streptococcus pyogenes. Infect. Immun. 62:1867-1874.

36. Norrby-Teglund, A., D. Newton, M. Kotb, S. E. Holm, and M. Norgren 1994. Superantigenic properties of the group A streptococcal exotoxin SpeF (MF). Infect. Immun. 62:5227-5233.

37. Chang, J. C. C., L. R. Smith, K. J. Froning, B. J. Schwabe, J. A. Laxer L. L. Caralli, H. H. Kurland, M. A. Karasek, D. I. Wilkinson, D. J. Carlo, and S. W. Brostoff. 1994. CD8 + TR cells in psoriatic lesions preferentially use Tcell receptor V $\beta 3$ and/or V $\beta 13.1$ genes. Proc. Natl. Acad. Sci. USA. 91:92829286.

38. Boehncke, W.-H., C. Küenzlen, T. M. Zollner, V. Mielke, and W. Sterry 1994. Predominant usage of distinct $\mathrm{T}$-cell receptor $\mathrm{Vb}$ regions by epidermotropic T cells in psoriasis. Exp. Dermatol. 3:161-163.

39. Valdimarsson, H., B. Baker, I. Jónsdóttir, and L. Fry. 1986. Psoriasis: a disease of abnormal keratinocyte proliferation induced by $\mathrm{T}$ lymphocytes. Immunol. Today. 7:256-259.

40. Schmitt-Egenolf, M., W.-H. Boehncke, M. Ständer, T. H. Eiermann, and W. Sterry. 1993. Oligonucleotide typing reveals association of type I psoriasi with the HLA-DRB $1 * 0701 / 2$, -DQA1 *0201, -DQB1 *0303 extended haplotype. J. Invest Dermatol 100:749-752.

41. McFadden, J., H. Valdimarsson, and L. Fry. 1991. Cross-reactivity between streptococcal M surface antigen and human skin. Br. J. Dermatol. 125:443447.

42. Shikhman, A. R., and M. W. Cunningham. 1994. Immunological mimicry between $N$-acetyl- $\beta$-D-glucosamine and cytokeratin peptides. J. Immunol 152:4375-4387.

43. Nestle, F. O., L. A. Turka, and B. J. Nickoloff. 1994. Characterization of dermal dendritic cells in psoriasis. J. Clin. Invest. 94:202-209.

44. Nickoloff, B. J., R. S. Mitra, J. Green, X.-G. Zheng, Y. Shimizu, C. Thompson, and L. A. Turka. 1993. Accessory cell function of keratinocytes for superantigens: dependence on lymphocyte function-associated antigen-1/intercellular adhesion molecule-1 interaction. J. Immunol. 150:2148-2159. 